A Teoria da Ressonância Não-Sincronizada das Ligações Covalentes

Costa, M. B. S.;* Barros, K. A.

Rev. Virtual Quim., 2012, 4 (2), 130-145. Data de publicação na Web: 15 de maio de 2012

http://www.uff.br/rvq

\title{
Unsynchronized Resonating of Covalent Bond Theory
}

Abstract: The fundamental features of the unsynchronized resonating of covalent bond (RVB) theory as originally developed by Linus Pauling are presented. The resonance of covalent bonds is widely known by chemists; however, the idea of unsynchronized resonance is unfamiliar. Nevertheless, the versatility of the RVB theory can be seen in the investigation of many systems and phenomena, such as superconductivity, magnetism, catalysis, besides the description of the metals, alloys and intermetallic compounds. The RVB theory has the advantage of relating the properties of a system with the nature of the atoms that constitute it.

Keywords: Unsynchronized resonance; covalent bond; metallic bond; RVB theory.

\section{Resumo}

São apresentados os conceitos fundamentais da teoria da ressonância não-sincronizada das ligações covalentes (RVB), como originalmente desenvolvida por Linus Pauling. A ressonância de ligações covalentes é amplamente conhecida pelos químicos, contudo, a noção da ressonância não-sincronizada é pouco familiar. Não obstante, a versatilidade da teoria RVB pode ser vista na abordagem de vários sistemas e fenômenos como supercondutividade, magnetismo, catálise, além da descrição de metais, ligas e compostos intermetálicos. A teoria RVB tem a vantagem de relacionar as propriedades de um sistema com a natureza dos átomos que o constitui.

Palavras-chave: Ressonância não-sincronizada; ligação covalente; ligação metálica; teoria RVB.

\footnotetext{
* Universidade Federal de Pernambuco, Departamento de Química Fundamental, Centro de Ciências Exatas e da Natureza, Av. Prof. Moraes Rego, 1235, Cidade Universitária, CEP 50670-901, Recife, PE, Brasil.

M marconi.costa@ufpe.br
} DOI: 10.5935/1984-6835.20120011 


\title{
A Teoria da Ressonância Não-Sincronizada das Ligações Covalentes
}

\author{
Marconi B. S. Costa, ${ }^{*}$ Karina A. Barros
}

Universidade Federal de Pernambuco, Departamento de Química Fundamental, Centro de Ciências Exatas e da Natureza, Av. Prof. Moraes Rego, 1235, Cidade Universitária, CEP 50670-901, Recife, PE, Brasil.

* marconi.costa@ufpe.br

Recebido em 12 de dezembro de 2011. Aceito para publicação em 4 de maio de 2012

\section{Introdução}

\section{A ligação metálica}

\section{O orbital metálico}

4. A função de onda RVB: o exemplo do lítio

5. O princípio da eletroneutralidade

6. A classificação dos átomos

7. Cálculo do número de estruturas RVB

8. Uma visão química do estado sólido

\section{Introdução}

Apesar de não ter alcançado popularidade equivalente à de outras teorias, a teoria da ressonância não-sincronizada das ligações covalentes (RVB, do inglês resonating valence bond), vem sendo aplicada com sucesso a uma variedade de casos e fenômenos distintos. Originalmente desenvolvida por Pauling ${ }^{1-16}$ para explicar as propriedades dos metais, ela contempla ainda a supercondutividade ${ }^{15}$ e 0 magnetismo. $^{16}$ Sua versatilidade tem sido demonstrada por outros autores, ${ }^{17-30}$ dos quais destacamos Pavão et al. ${ }^{17-25}$ Estes a utilizam no estudo da supercondutividade, ${ }^{17-20}$ carcinogênese química, ${ }^{21}$ mecanismo de interação de moléculas com superfícies metálicas, ${ }^{22}$ condutividade elétrica no lítio, $^{23}$ formação e estabilidade do $\mathrm{O}_{4}{ }^{24}$ e magnetismo. ${ }^{25}$ Outros autores também têm obtido êxito empregando-a no estudo da supercondutividade, ${ }^{26}$ na pesquisa de metais, ligas e compostos intermetálicos, ${ }^{27}$ na interpretação da condutividade elétrica em sistemas orgânicos $1 D,{ }^{28}$ na implementação de novos métodos computacionais, ${ }^{29}$ dentre outros. $^{30}$

A despeito do sucesso da teoria em campos de pesquisa distintos, os químicos ainda possuem pouca familiaridade com o tema. Enquanto a ressonância sincronizada das ligações covalentes é amplamente conhecida e discutida em livros de química, a ressonância não-sincronizada permanece até certo ponto ignorada. Uma das principais razões disso é o fato dos químicos terem pouca tradição na pesquisa dos metais, área na qual o conceito da ressonância não-sincronizada foi originado $o^{1-16}$ e onde os físicos detêm grande influência. Por esta razão, a contribuição de Anderson ${ }^{31}$ para o desenvolvimento da teoria RVB se tornou mais popular que a de Pauling. Contudo, a literatura apresenta trabalhos ${ }^{28}$ que corroboram ambas as propostas demonstrando que são equivalentes e complementares. Destacaremos aqui o modelo de Pauling. Vale ressaltar que apesar do seu sucesso em campos de pesquisa distintos, a teoria RVB de Pauling é pouco aceita na comunidade científica que trabalha com metais, área em que a teoria de bandas é 
amplamente empregada. Conceitualmente, a teoria de bandas é relacionada à teoria dos orbitais moleculares, o que favoreceu o seu uso ao longo dos anos, em detrimento da proposta de Pauling. Esta acabou sendo adotada apenas por poucos grupos de pesquisa no mundo, o que não significa necessariamente que os conceitos de sua teoria sejam inadequados. A sua versatilidade pode ser facilmente atestada na literatura. ${ }^{1-30}$ Outra importante razão para sua pouca popularidade é a necessidade de grandes recursos computacionais requeridos em cálculos do tipo Valence Bond, ${ }^{29,32}$ o que inviabiliza o emprego deste método em sistemas de interesse químico e físico. Neste cenário, as estratégias desenvolvidas por Pavão et al. ${ }^{17-25}$ demonstraram ser bastante úteis no uso da teoria RVB em campos de pesquisa distintos.

O conceito de ressonância não pode ser confundido com o conceito da deslocalização. ${ }^{33}$ É errado considerar a deslocalização como equivalente à estabilização por ressonância. A molécula $\mathrm{HCl}$ pode ser usada como exemplo uma vez que ela pode ser considerada como um híbrido de ressonância de uma estrutura covalente e outra iônica. Sua estrutura covalente tem um peso maior do que $50 \%$. O efeito da estabilização de ressonância da estrutura covalente pela estrutura iônica resulta numa localização maior dos elétrons de valência no anion $\mathrm{Cl}^{-}$e menos deslocalizado sobre os dois centros do que na estrutura puramente covalente. Outro exemplo é a molécula $\mathrm{H}_{2}$. Há uma probabilidade diferente de zero de se observar uma distribuição de cargas que pode ser descrita como $\mathrm{H}^{+} \mathrm{H}^{-}$ou $\mathrm{H}^{-} \mathrm{H}^{+}$ (além é claro da probabilidade diferente de zero de se observar uma estrutura que corresponda à usual ligação covalente). Restringindo a função de onda para excluir qualquer destas contribuições a energia obtida será maior que aquela do estado fundamental e sua descrição será menos precisa. A saída então é incorporar ao cálculo ambas contribuições, a iônica e a covalente. Este processo de adicionar contribuições iônicas é conhecido como mistura de configurações ou interação de configurações. Em adição, esse processo é chamado de estabilização por ressonância e a energia mais baixa obtida com a sua utilização é a energia de ressonância. Uma vez que essa discussão é objeto de muita confusão na literatura e entre os químicos, sugere-se ao leitor a consulta do artigo citado na referência 33 onde o autor aborda o tema de forma satisfatoriamente esclarecedora.

É importante destacar que Pauling ${ }^{6}$ foi um dos pioneiros ao propor uma teoria do ponto de vista químico para os metais. A descoberta de substâncias como $\mathrm{KHg}_{13}, \mathrm{Cu}_{5} \mathrm{Zn}_{8}, \mathrm{Cu}_{31} \mathrm{Sn}_{8}, \mathrm{Fe}_{5} \mathrm{Zn}_{21}$ e $\mathrm{NaZn}_{13}$ são

Rev. Virtual Quim. |Vol 4| | No. 2| |130-145| exemplos de compostos que deixavam os químicos em situação desconcertante, ${ }^{8}$ pois eram incapazes de explicar a ocorrência de tais estruturas pelas teorias vigentes na época. Pauling foi o primeiro ${ }^{1-16}$ a desenvolver um modelo capaz de elucidar sistemas dessa natureza, usando para isso, conceitos como o do orbital metálico e da ressonância não-sincronizada das ligações covalentes. Ele mostrou ${ }^{6}$, também, que as conclusões obtidas com a teoria do orbital molecular acerca dos metais poderiam ser incorporadas sem grande mudança para dentro da linguagem da teoria RVB, um fato que reforçou ainda mais a aplicabilidade do seu modelo. Pauling mostrou $^{6}$, ainda, que a sua teoria é compatível com a existência das zonas de Brillouin e que permite reproduzir o mesmo número de elétrons contidos em importantes poliedros de Brillouin para metais e ligas. Sua proposta tem a vantagem de descrever com simplicidade as propriedades dos metais, ligas e compostos intermetálicos usando uma linguagem comum aos químicos. Neste trabalho, são apresentados os principais conceitos da teoria RVB nos termos originais que foram empregados por Pauling em seu desenvolvimento.

\section{A ligação metálica}

Em 1938, Pauling deu o passo inicial ${ }^{6}$ para o desenvolvimento da teoria RVB. Com o interesse em descrever as forças interatômicas nos metais, ele chegou à conclusão que a ligação metálica poderia ser encarada como uma ligação covalente simples. Pauling propôs que a ligação covalente nos metais ressona entre as posições disponíveis no caso em que o número de posições excede o número de ligações. O exemplo mais frequente citado por Pauling ${ }^{1-16}$ é o do cristal de lítio (Li), o qual possui a estrutura cúbica de corpo centrado onde cada átomo de lítio está ligado a 8 átomos nos vértices do cubo e a mais 6 átomos nos centros dos cubos adjacentes. O $L i$ forma apenas uma ligação através do seu elétron $2 s$, porém, há oito posições próximas e seis mais distantes onde esta ligação pode se encontrar. Deste modo, a ligação se encontra em ressonância nas 14 posições acessíveis. Além disso, Pauling admitia que todos ou a maioria dos elétrons externos dos metais (inclusive os de transição) participavam na formação de ligações. Esse ponto de vista fornece uma explicação qualitativa satisfatória das propriedades dos metais como dureza, compressibilidade, capacidade térmica a baixas temperaturas, coeficiente de expansão térmica, a tendência geral das distâncias interatômicas, as propriedades magnéticas, etc. ${ }^{1-16}$ 
A partir de investigações das propriedades físicas dos metais, ele concluiu que na sequência de átomos $K, C a, S c, T i, V, C r$, o número de ligações cresce de 1 até aproximadamente 6 , permanecendo constante do $\mathrm{Cr}$ ao $\mathrm{Ni}$, para a partir deste elemento diminuir. A redução na distância interatômica observada nesta seqüência de átomos foi encarada por Pauling como resultado do aumento no número de ligações covalentes. Além disso, o aumento na dureza, resistência e ponto de fusão poderiam ser atribuídos ao incremento de 1 a 6 no número de ligações covalentes formadas por estes átomos. Pauling rejeitava a alegação de pesquisadores que afirmavam que apenas os elétrons $s$ eram os responsáveis pela coesão dos metais de transição. Para ele, as propriedades exibidas pelos metais mostram claramente que as ligações envolvem interações de um grande número de elétrons. Se apenas os elétrons $s$ participassem da interação, os metais deveriam ser moles, fracos, ter baixo ponto de fusão, etc. Contudo, o que se observa é o oposto. Sua proposta foi reforçada pelas propriedades magnéticas de alguns átomos, como o vanádio. A configuração normal do vanádio é $3 d^{3} 4 s^{2}$. Se apenas os dois elétrons $4 s$ estivessem envolvidos na ligação, o vanádio deveria apresentar um grande momento de dipolo magnético pelos elétrons $3 d^{3}$, e consequentemente, deveria mostrar ferromagnetismo ou grande paramagnetismo, decrescendo em magnitude com o aumento da temperatura. Porém, o vanádio é fracamente paramagnético e seu paramagnetismo é quase independente da temperatura. Esse comportamento é esperado se todos os elétrons externos tomam parte na formação da ligação, como sugerido por Pauling. ${ }^{6}$ Ele reforça ainda mais sua proposta admitindo que apesar de os orbitais $d$ serem inapropriados para formação de ligações, a hibridização de orbitais $3 d$ com orbitais $4 s$ e $4 p$, resulta em orbitais adequados para formação de ligações. ${ }^{13}$ Do mesmo modo que no carbono os orbitais $s$ e $p$ hibridizam para formar quatro ligações, Pauling admitia que nos metais de transição a hibridização dos orbitais $d s p$ justificava o aumento na formação do número de ligações.

Ainda em 1938, Pauling publicou uma curva (denominada curva Pauling-Slater) ${ }^{1,8,6}$ do momento magnético para algumas ligas binárias ( $\mathrm{Fe}-\mathrm{Cr}, \mathrm{Fe}-\mathrm{V}, \mathrm{Fe}$ $\mathrm{Ni}, \mathrm{Fe}-\mathrm{Co}, \mathrm{Ni}-\mathrm{Co}, \mathrm{Ni}-\mathrm{Zn}, \mathrm{Ni}-\mathrm{Cu}$ ). Esta curva mostra que o momento magnético cresce até $\approx 2,5 \mu_{B}$ (magnétons de Bohr) para a liga $\mathrm{Fe}_{72} \mathrm{CO}_{28}$ e decresce a zero para a liga $\mathrm{Ni}_{44} \mathrm{Cu}_{56}$. Assumindo que cada uma das seis ligações nos átomos que constituem as ligas requer um orbital, Pauling concluiu que, para os metais de transição, apenas 8,28 dos nove orbitais de valência (um $4 s$, cinco $3 d$ e três $4 p$ ) são ocupados por elétrons e 0,72 orbital por átomo, em média, permanece sem qualquer uso aparente e foi interpretado por ele na época como instável. A liga de $\mathrm{Fe}_{72} \mathrm{CO}_{28}$, por exemplo, possui 8,28 elétrons de valência por átomo. $\mathrm{O} F$ possui 8 elétrons de valência $\left(4 s^{2} 3 d^{6}\right)$ e o Co tem 9 $\left(4 s^{2} 3 d^{7}\right)$. Na liga $\mathrm{Fe}_{72} \mathrm{CO}_{28}$ há $576(72 \times 8)$ elétrons de valência em função dos átomos de Fe e 252 (28x9) elétrons de valência em função dos átomos de Co. Somando 576 com 252 temos 828 elétrons de valência para a liga $\mathrm{Fe}_{72} \mathrm{CO}_{28}$. Como há 100 átomos para cada 828 elétrons de valência, então há em média 8,28 elétrons de valência por átomo. Uma vez que há 9 orbitais dsp hibridizados no Fe e no Co, 8,28 estão ocupados por elétrons enquanto 0,72 estão vazios. Destes 8,28 orbitais ocupados, 2,5 contém os elétrons responsáveis pelo momento magnético da liga $\left(2,5 \mu_{\mathrm{B}}\right)$ que não tomam parte na formação de ligação. Logo, subtraindo 8,28 pelo valor do momento magnético 2,5 , o resultado é a valência ${ }^{8}$ do $\mathrm{Fe}$ e do Co: 5,78. Seguindo raciocínio similar Pauling determinou as valências de vários metais.

Até esse momento nenhuma menção tinha sido feita por ele quanto à ressonância não-sincronizada da ligação covalente. Mesmo em 1947 quando usou novamente sua teoria para propor uma relação entre a ligação covalente e a ligação metálica, ${ }^{6,8}$ Pauling não fez menção sobre a ressonância não-sincronizada. Foi somente em 1948 que o termo foi empregado pela primeira vez no estudo dos metais, como veremos a seguir.

\section{0 orbital metálico}

Apesar de conhecida e amplamente aplicada a sistemas orgânicos, ${ }^{8}$ Pauling foi o primeiro a usar a teoria da ressonância das ligações covalentes para os metais. ${ }^{6}$ Ele fez referência á ressonância nãosincronizada da ligação covalente somente em 1948, quando introduziu um novo conceito: o orbital metálico. ${ }^{6}$ Pauling propôs que os 0,72 orbitais sem uso aparente desempenham a função de permitir a ressonância não-sincronizada das ligações covalentes, o que resulta no estado de mais baixa energia para o sistema. Para ele, a característica essencial dos metais é a possessão deste orbital metálico por cada átomo ou muitos átomos na fase metálica em adição aos orbitais normalmente ocupados por elétrons. $O$ valor aproximado de 0,72 para o orbital metálico pode ser obtido não apenas através do estudo das propriedades magnéticas de átomos e ligas metálicas, ${ }^{6}$ mas também pela análise das valências 
dos átomos que constituem a cerâmica supercondutora $\mathrm{YBa}_{2} \mathrm{Cu}_{3} \mathrm{O}_{\delta}{ }^{1,8}$ pela estrutura do estanho branco e cinza, 6,8 por um tratamento estatístico da teoria RVB, ${ }^{1-9}$ pelo cálculo da ocorrência de cátions e ânions no metal, ${ }^{6}$ etc.

O papel do orbital metálico pode ser contemplado no exemplo a seguir. O Esquema 1 apresenta os dois tipos de ressonância: a sincronizada e a não- sincronizada, em um quadrado formado por átomos de Li (uma representação do cristal). É importante destacar que este exemplo considera apenas o caso bidimensional, no qual há um número duas vezes maior de estruturas ressonantes não-sincronizadas em relação à sincronizada. Se levássemos em conta o caso tridimensional, a diferença seria ainda maior.

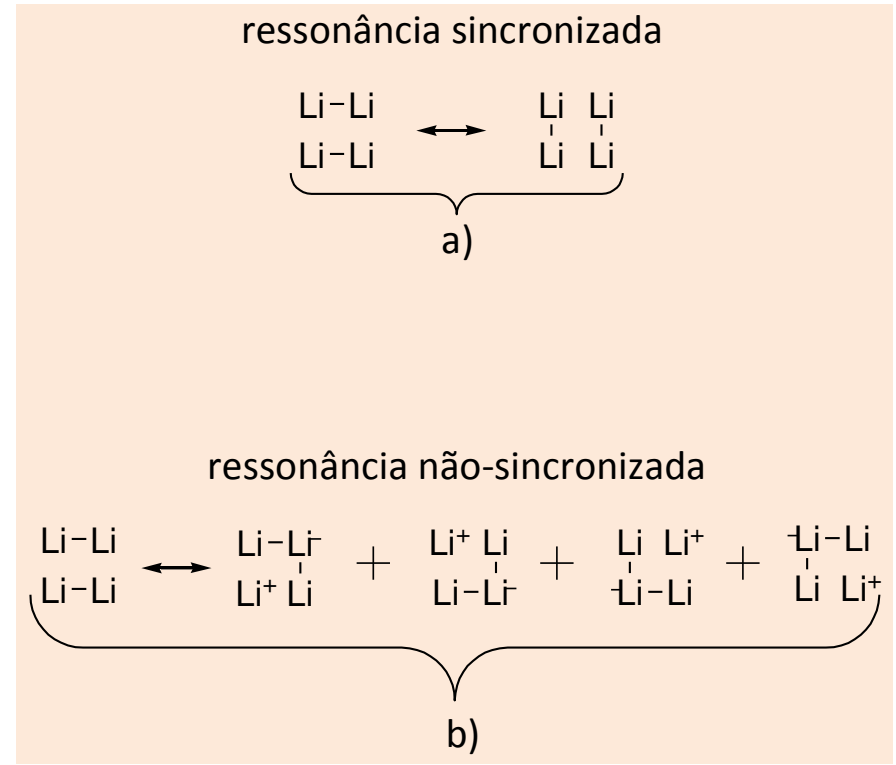

Esquema 1. Exemplo de a) ressonância sincronizada e b) não-sincronizada, ambas empregando um quadrado de átomos de lítio (uma representação do cristal) como ilustração ${ }^{6}$

A ressonância não-sincronizada leva a uma estabilização maior, tendo em vista o grande número de estruturas associadas. ${ }^{1-8}$ Ao incorporar no cálculo as contribuições iônicas e covalentes, o resultado é um abaixamento da energia do sistema em estudo pois leva em conta efeitos até então ignorados. Esse processo é chamado de estabilização de ressonância e a energia mais baixa obtida com a sua utilização é a energia de ressonância. ${ }^{33}$ Cada átomo de $L i$ tem um elétron de valência que permite a formação de uma ligação simples para cada par de átomos. Se todos os átomos devem permanecer neutros, a estabilização obtida através da ressonância sincronizada deve ser relativamente pequena. A ressonância sincronizada ocorre por que o número de posições (4) das ligações é maior do que o número de ligações (2), então as ligações podem mudar de uma posição para outra em sincronia, com pares de ligações mudando de posições simultaneamente (Esquema 1a). Contudo, o orbital metálico permite que o número de coordenação de um átomo seja maior do que o seu número de elétrons de valência e de orbitais de ligação, ${ }^{6}$ o que leva à ressonância não-sincronizada (Esquema 1b). O conceito de ressonância não- sincronizada reflete a ideia das ligações mudarem de posição independentemente umas das outras (sem sincronia), permitida pelo orbital metálico. Pauling destaca que alguns modos de ressonância devem ter maior contribuição do que outros ${ }^{6}$ e que a energia resultante do uso do orbital metálico supera a energia de repulsão dos átomos adjacentes não ligados, resultando em maior estabilidade para o sistema. ${ }^{1-8}$ Além disso, Pauling concluiu que nem todos os átomos de um metal devem possuir um orbital metálico para que a ressonância não-sincronizada ocorra. De modo semelhante, para um dado átomo incrementar o número de ligantes além do que sua valência permite, não é necessário que ele possua um orbital extra: é suficiente que esteja cercado por átomos que possuam orbital extra. Então, a ligação deste átomo central pode mudar de posição entre as posições alternativas. ${ }^{1-9}$

Pelo Esquema 1 conclui-se que a ressonância sincronizada leva a um estado isolante enquanto que a não-sincronizada leva a um estado condutor, pois nesta há separação de cargas. O processo da condutividade elétrica pode ser descrito por este mecanismo como mostra o Esquema 2. 


\author{
M-M M-M M-M M-M M-M M-M \\ $M-M \quad M-M \quad M^{+} M-M-M \quad M-M \quad M-M$ \\ $M-M M^{+} M-M \quad M-M \quad M-M-M \quad M-M$ \\ $\mathrm{M}^{+} \mathrm{M}-\mathrm{M} \quad \mathrm{M}-\mathrm{M} \quad \mathrm{M}-\mathrm{M} \quad \mathrm{M}-\mathrm{M} \quad \mathrm{M}-\mathrm{M}-\mathrm{M}$
}

Esquema 2. Mecanismo RVB da condutividade elétrica nos metais $(M)^{1}$

De modo similar, o espalhamento de elétrons por fônons também pode ser contemplado pelo mecanismo RVB. ${ }^{6} \mathrm{O}$ encurtamento e o alongamento temporário no comprimento das ligações devido às agitações térmicas interferem na ressonância nãosincronizada, de modo que a ressonância ocorre mais frequentemente entre posições de mesma energia do que em posições de energia diferente. Com o aumento da temperatura, cresce o número de estados em que há posições de energia diferente, diminuindo a ressonância não-sincronizada e resultando em baixa condutividade. ${ }^{6,8}$

Outras propriedades características dos metais podem ser descritas qualitativamente em termos da transferência de cargas positivas e negativas de um átomo para outro acompanhando a ressonância nãosincronizada da ligação covalente. Por exemplo, a maleabilidade e a ductilidade: quando os metais são deformados, os átomos formam novas ligações de mesma intensidade com seus vizinhos, dando estabilidade ao novo sistema. ${ }^{8}$ Pauling mostrou que a energia de ressonância é a principal responsável pela diferença de energia entre o cristal e as moléculas diatômicas no estado gasoso. ${ }^{8}$

Outro exemplo que ilustra a função do orbital metálico é dado pelo estanho $(S n)$. O $S n$ possui duas formas alotrópicas: uma de cor cinza e isolante com estrutura cúbica, outra de cor branca e condutora de estrutura tetragonal. ${ }^{1,6}$ Sua configuração eletrônica é $4 d^{10} 5 s^{1} 5 p^{3}$ para a fase isolante, e $4 d^{10} 5 s^{2} 5 p^{2}$ para a metálica. ${ }^{6,8} \bigcirc S n$ isolante forma quatro ligações covalentes através dos orbitais híbridos $s p^{3}$ e não há orbital extra para servir como orbital metálico. No $S n$ metálico cada átomo está ligado a outros seis átomos e as ligações ressonam entre as posições alternativas. Esta forma do $S n$ possui um orbital que pode servir como orbital metálico. Pauling ${ }^{8}$ admite que estas duas formas do $S n$ estão presentes no metal numa proporção de 3:1 (metálico:isolante), o que resulta numa valência aproximada de 2,5 . Ele concluiu que a valência dos metais de transição não é o número de elétrons desemparelhados obtido distribuindo-os entre os nove orbitais $s p d$, mas um número menor alcançado distribuindo os elétrons entre oito orbitais e o nono (cerca de 0,72 ) reservado para uso como orbital metálico. ${ }^{6}$ De um modo geral, a valência metálica mostrada pelos metais de transição é uma média que corresponde à ressonância de cada átomo entre duas ou mais estruturas eletrônicas com valência inteira. ${ }^{8}$ Os valores das valências dos metais foram revisados posteriormente ${ }^{16}$ e serão abordados adiante. Em adição, é importante destacar que o número de átomos vizinhos em um metal é maior do que ele pode formar com seus elétrons de valência. Uma vez que não há motivo aparente para definir certas posições de ligações no cristal em detrimento de outras, uma perspectiva plausível é que todos os átomos vizinhos estejam ligados entre si. Essa possibilidade é razoável considerando a ocorrência da ressonância não-sincronizada.

Uma vez definido o papel do orbital metálico, Pauling ${ }^{6,8,9}$ classificou os nove orbitais spd híbridos em três classes: orbitais $s p d$ de ligação, orbitais $s p d$ contraídos responsáveis pelo momento magnético e o orbital metálico. Um importante resultado deste conceito é que toda substância que possui um orbital metálico ou que tenha um orbital para atuar como orbital metálico, é um metal. ${ }^{8,9}$ Semelhantemente, toda substância metálica deve necessariamente ter orbital metálico. Uma aparente exceção a esta regra é o boro $(B))^{3,7-9} \mathrm{Em}$ sua estrutura cristalina tetragonal há quatro clusters de $B_{12}$ dispostos em forma de icosaedro e outros dois átomos de $B$ tetraligantes. Cada átomo de $B$ tem número de coordenação igual a seis, enquanto os dois tetraligantes tem número de coordenação quatro. Pauling ${ }^{6}$ calculou que nessa estrutura a ressonância não-sincronizada resulta em $44 \%$ de $B^{0}, 28 \%$ de $B^{+}$e $28 \%$ de $B^{-}$. Porque então o $B$ não apresenta propriedades metálicas características? O mecanismo da ressonância não-sincronizada envolve o movimento de uma ligação em torno de um átomo. Nos clusters de $B_{12}$, contudo, o arranjo dos átomos é tal que não permite transferência de carga de um grupo $B_{12}$ para outro pelo mecanismo RVB, ${ }^{1,3,8,9}$ de modo que a ressonância restringi-se ao interior de cada grupo $B_{12}$, havendo pouca ressonância entre os 
clusters. Logo, a condutividade elétrica será muito pequena, o que se verifica experimentalmente.

Apesar de não ter encontrado evidências da existência do orbital metálico na estrutura de bandas dos metais, ${ }^{6}$ Pauling verificou uma relação entre o número de elétrons de ligação dado pelo seu sistema de valências metálicas e o número de elétrons contidos em um importante poliedro de Brillouin para algumas ligas e metais. ${ }^{1,6,8}$ Esse é o resultado mais próximo da teoria de bandas que Pauling obteve com o uso de sua teoria RVB. Na seção seguinte é apresentada a função de onda RVB dada por Pauling ${ }^{14}$

$$
\psi=\sum_{i=1}^{M} a_{i} \psi_{i}
$$

onde

$$
\psi_{i}=2^{-\frac{1}{2} N} \sum_{R}(-1)^{R}\left[\{(2 N) !\}^{-\frac{1}{2}} \sum_{P}(-1)^{P} P a(1) \beta(1) b(2) \alpha(2) \ldots\right],
$$

é a função de onda representando um dos $M$ modos de distribuir as ligações de valência entre as posições interatômicas no metal de tal modo que cada átomo forme uma ligação. ${ }^{6} P$ é o operador de permutação, $R$ é a operação de exchange das funções de spin $\alpha$ e $\beta$ dos orbitais ligados com $a$ e $b,(-1)^{R}$ é igual a +1 para um número par de exchange e -1 para um número

$$
W=W_{\text {ligação }}+W_{\text {ressonância }}
$$

na qual $W_{\text {ligação }}=\int \psi_{i}^{*} H \psi_{i} d \tau$ é a energia de qualquer uma das estruturas de ligação de valência $\psi_{i} \mathrm{e}$

$$
W_{\text {ressonância }}=\sum_{i=1}^{M} \sum_{j \neq i} a_{i} a_{j} K_{i j}=2 \sum_{j=2}^{M} K_{1 j}
$$

é a energia de ressonância, sendo $K_{i j}$ a integral de ressonância $\int \psi_{j}^{*} H \psi_{j} d \tau$, entre duas estruturas $i$ e $j$ da ligação de valência.

Pauling propôs um exemplo onde mostrou a possibilidade de relacionar os resultados obtidos em sua teoria com àqueles alcançados com a teoria de bandas, onde prevalece a discussão das conhecidas zonas de Brillouin. No exemplo, ${ }^{6}$ a função de onda é ímpar. A convenção adotada é inicialmente designar a função spin $\alpha$ para o orbital $b, \beta$ para o orbital $a$, etc. ${ }^{14}$ Se as funções de onda $\psi_{i}$ são equivalentes e ortogonais, $a_{i}$ deve igualar-se a $M^{-\frac{1}{2}}$, e a energia (representada por $W$ ) do estado normal pode ser escrita como e sua estratégia de relacionar alguns resultados de

\section{A função de onda RVB: o exemplo do} apresentada por Pauling em 1949 usando o cristal de $L i$ como um exemplo. ${ }^{6,8}$ Para o cristal, a função é dada por 


$$
\phi_{i j}(1,2)=\mathrm{C}\left\{\phi_{i}(1) \phi_{j}(2)+\phi_{j}(1) \phi_{i}(2)\right\}\{\alpha(1) \beta(2)-\beta(1) \alpha(2)\},
$$

com $\phi_{i}$ e $\phi_{j}$ sendo os orbitais de ligação hibridizados dos átomos $a_{i}$ e $a_{j}$, e $\alpha$ e $\beta$ as funções spin de um elétron. As $\phi_{i j}$ podem ser usadas na construção de funções anti-simetrizadas correspondendo às possíveis estruturas de ligação de valência para o cristal. Este procedimento leva aos mesmos resultados dados pelas equações (1) e (2). Uma aproximação útil é feita ignorando a energia de ressonância entre os pares de elétrons ligados e

$$
\psi(1,2, \ldots, 2 N)=\Phi_{1}(1,2) \Phi_{2}(3,4),
$$

onde cada função $\Phi_{k}$ é uma função de dois elétrons representando uma ligação de valência em ressonância no cristal. A energia total nesta aproximação é a soma das energias das ligações ressonantes:

$$
W=2 W_{k}
$$

A forma das funções $\Phi_{k}$ pode ser muito similar à dos orbitais moleculares. Se há $M$ posições interatômicas no cristal que podem ser ocupadas por qualquer uma das $N$ ligações de pares de elétrons, então as $M$ funções $\phi_{i j}$ podem ser combinadas dentro de $M$ agregados lineares mutuamente ortogonais que aproximam as soluções da equação de onda com a inclusão dos termos de interação representando a ressonância. Esta combinação pode ser feita com uso do fator de Bloch:

$$
\Phi_{k}(1,2)=C \phi_{r}(1,2) \mathrm{e}^{2 \pi i P k . r / h}
$$

Aqui $r$ é o vetor raio da origem até um ponto $R$ no cristal, $\phi_{r}$ é a função da electron-pair-bond na região próxima a $R, \boldsymbol{P}_{k}$ é o vetor momentum correspondendo aos três números quânticos $k, h$ é a constante de Planck e $C$ é o fator de renormalização.

Quando o vetor momentum $\boldsymbol{P}_{k}$ tem magnitude e orientação que correspondem às reflexões de Bragg de um importante plano cristalográfico, fortes interações entre a ligação ressonante e o resto do cristal deverão ocorrer, levando a um deslocamento dos níveis de energia e à formação de zonas de Brillouin. ${ }^{6}$ Em 1948, Pauling encontrou uma notável concordância entre o número de elétrons de ligação considerando apenas a energia da ligação e a energia de ressonância de cada ligação entre suas posições alternativas, sem correlacionar sua ressonância com a de outras ligações. Isto permite introduzir facilidades ao método de modo a torná-lo mais prático sem comprometer sua eficácia. A função de onda para o cristal (não anti-simetrizada) pode então ser escrita como

dado pelo seu sistema de valências metálicas e o número de elétrons contidos em um importante poliedro de Brillouin para algumas ligas metálicas. ${ }^{6,8}$ Esta concordância dava suporte à sua teoria tornando-a mais convincente na tarefa de descrever sistemas metálicos. Tendo em vista a necessidade de grandes recursos computacionais exigidos em cálculos do tipo Valence Bond, ${ }^{29,32}$ o método proposto por Pauling não alcançou popularidade. Apenas pequenos clusters de lítio foram alvo de alguns estudos, ${ }^{20,23,27}$ dada a relativa simplicidade do sistema. Apesar disso, Pauling verificou através de aproximações que a energia do sistema é mínima quando o cristal metálico contém aproximadamente $44 \%$ de átomos neutros, $28 \%$ de cátions e $28 \%$ de ânions. ${ }^{6,8}$ Este resultado nos leva direto ao princípio da eletroneutralidade.

\section{O princípio da eletroneutralidade}

O princípio da eletroneutralidade proposto por Pauling ${ }^{10}$ admite que o número de átomos com cargas positivas é aproximadamente igual ao número de átomos com cargas negativas e que o número de átomos neutros é aproximadamente igual à soma dos átomos positivos e negativos. Sob a condição de que há um orbital disponível, a estrutura eletrônica das substâncias é tal que a carga resultante nos átomos não supera \pm 1 , correspondendo às valências $v$ - 1 e $v+1$ e estão distribuídas de um modo que corresponde a estabilidade eletrostática. ${ }^{6,8,10}$ Este princípio limita a ocorrência dos átomos nos estados $M^{+}, M^{0}$ e $M^{-}(M$ representa um metal). $\mathrm{O}$ cátion possui dois orbitais vazios, o átomo neutro um (o orbital metálico), e o ânion não possui nenhum. A probabilidade das espécies $M^{+}$e $M^{-}$é menor do que para $M^{0}$ por causa 
da energia de separação de cargas $^{6}$ (Pauling destaca que a tendência dos átomos serem eletricamente neutros é uma característica de compostos estáveis).

Esta configuração de cargas permite visualizar o mecanismo RVB da transferência de elétrons de forma simples: $M-M M-M \rightarrow M^{+} M-M^{-}-M$. Segundo Pauling, uma vez que as ligações estão em ressonância, o par de elétrons migra de uma posição para outra de forma não-sincronizada por causa do orbital metálico que o átomo receptor possui. 0 átomo receptor passa do estado $M^{0}$ para $M^{-}$, e não pode mais aceitar outra ligação porque é energeticamente desfavorável. O átomo doador passa de $M^{0}$ para $M^{+}$, e o resultado é um estado condutor, pois há separação de cargas. Sob a ação de um campo elétrico estas cargas percorrem o metal, caracterizando a condutividade elétrica. ${ }^{1-8}$ Além disso, Pauling verificou que as ligações ressonam com uma frequência a qual determina o número de vezes que uma ligação muda de uma posição para outra de forma não-sincronizada. ${ }^{6}$ A frequência da ressonância é determinada pela energia de ressonância que segundo Pauling, é cerca de uma ordem de magnitude menor do que a energia de ligação de um elétron de valência. ${ }^{1,8}$ Aqui é oportuno destacar que a densidade eletrônica derivada do modelo Valence Bond (VB) é independente do tempo, enquanto que o processo de transferência de elétrons é dependente do tempo. Deste modo, ao calcular a densidade eletrônica empregando o modelo $\mathrm{VB}$, não é possível obter informações sobre eventos dinâmicos. É errado pensar que se obtêm informações dependentes do tempo usando um método independente do tempo. As migrações de elétrons de um átomo para outro como ressonâncias não-sincronizadas são descrições qualitativas da transferência de carga nas quais Pauling admite ser viável para interpretar inclusive o fenômeno da corrente elétrica sob ação de um campo elétrico. Do mesmo modo, a frequência de ressonância mencionada por Pauling é indiretamente inferida pela energia de ressonância. É sabido que se pode obter alguma informação sobre o movimento do sistema quando o Hamiltoniano possui constantes ligadas a um dado processo, como por exemplo, no caso do oscilador harmônico em que a constante de força é relacionada com a frequência de oscilação a partir de um modelo independente do tempo. Contudo, nenhuma informação é obtida sobre a evolução temporal do oscilador. Uma vez que as descrições adotadas por Pauling são qualitativas e se referem a eventos dinâmicos como a corrente elétrica, o leitor deve evitar a confusão criada por interpretações típicas de fenômenos dependentes do tempo ao se usar inferências oriundas de descrição teórica independente do tempo.

Mesmo assim, os estados $M^{+}, M^{0}$ e $M^{-}$previstos pela teoria RVB são encontrados em cálculos diversos tais como em estudos de complexos de metais de transição e de materiais vítreos, ${ }^{30}$ supercondutores, ${ }^{17-}$ ${ }^{20}$ clusters metálicos, ${ }^{23,26}$ etc. Estes têm confirmado a validade do princípio da eletroneutralidade, reforçando o modelo de Pauling. Além deste princípio, outro importante conceito advindo da teoria RVB é a classificação dos átomos em hipereletrônicos, buffers e hipoeletrônicos, como a seguir será visto.

\section{A classificação dos átomos}

Em 1950, Pauling apresentou outro importante conceito, fruto de sua teoria: a classificação dos átomos em hipoeletrônicos, buffers e hipereletrônicos. ${ }^{11}$ Elementos hipoeletrônicos são deficientes em elétrons, pois possuem mais orbitais de ligação do que elétrons de valência (no estado neutro). Podem ampliar sua valência recebendo um elétron. Neste grupo estão incluídos os três primeiros elementos de cada período curto e os cinco primeiros de cada período longo (Figura 1). Os hipereletrônicos podem incrementar sua valência doando um elétron. Este grupo tem mais elétrons de valência do que orbitais de ligação. Nele estão incluídos os três últimos elementos (antes dos gases nobres) de cada período curto e os sete últimos elementos de cada período longo. Átomos buffers podem doar ou aceitar um elétron sem haver mudança em sua valência. Os cinco elementos $\mathrm{Cr}, \mathrm{Mn}, \mathrm{Fe}, \mathrm{Co}$ e $\mathrm{Ni}$ e seus congêneres nos outros dois períodos longos são buffers com respeito aos compostos metálicos. Eles podem doar um elétron $d$ não-ligante ou aceitar um elétron dentro da subcamada $d$ incompleta sem mudança na valência metálica. Os átomos de $C$ e Si possuem valência estável. No caso do $C$ qualquer adição ou remoção de um elétron resulta em decréscimo na valência. Já o $S i$ que também tem valência 4 , pode aumentá-la sob certas circunstâncias, fazendo uso dos orbitais externos $3 d$, 4 s e $4 p$. 


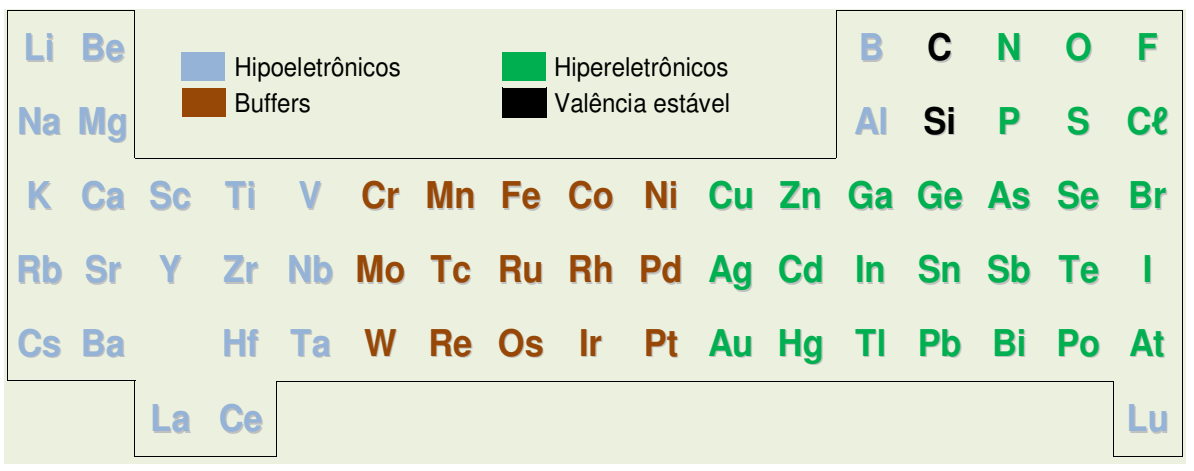

Figura 1. Classificação dos átomos em relação à valência segundo a teoria RVB ${ }^{11}$

Esta classificação pode ser facilmente compreendida observando a distribuição eletrônica dos elementos. Considere o Ti como exemplo. Sua configuração eletrônica é $[A r] 4 s^{2} 3 d^{2} 4 p$. Há 9 orbitais $d s p$ hibridizados e apenas 4 elétrons para ocupá-los. Esse átomo é hipoeletrônico, ou seja, possui mais orbitais disponíveis para formar ligações do que elétrons de valência. Outro exemplo, o $\mathrm{Cu}$. Sua configuração é $[A r] 4 s^{1} 3 d^{10} 4 p$. Com seus orbitais $d$ totalmente preenchidos, ele possui mais elétrons de valência do que orbitais disponíveis para formar ligações. Uma vez que há 9 orbitais $d s p$ hibridizados, sendo 0,72 o orbital metálico, então há 8,28 orbitais disponíveis para acomodar 11 elétrons. Deste modo, - Cu possui mais elétrons de valência do que orbitais disponíveis, sendo, portanto classificado como hipereletrônico.

Uma característica marcante nesta classificação de Pauling é a constatação de que ligas formadas por elementos hipo e hipereletrônicos possuem maior estabilidade do que outras formadas por diferentes combinações de metais. ${ }^{8,11}$ A estabilidade extra é adquirida pela transferência de um elétron de um átomo hipereletrônico para outro hipoeletrônico, resultando em $M^{+}$e $M^{-}$na proporção requerida pelo princípio da eletroneutralidade. ${ }^{10}$ Esse efeito é relevante em substâncias como $\mathrm{NaZn}_{13}$, pouco importante em sistemas do tipo $\mathrm{Al}_{9} \mathrm{CO}_{2}$ e insignificante em casos como $\mathrm{Cu}_{5} \mathrm{Zn}_{8}$ e $\mathrm{Na}_{2} \mathrm{~K}^{8,11}$ Vale ressaltar que há casos em que a transferência de elétrons pode ocorrer em compostos de dois átomos da mesma classe, ${ }^{11}$ contudo, nas ligas de metais hipo com elementos hipereletrônicos o efeito é mais pronunciado.

Pauling observou ainda que em muitas ligas formadas com esta combinação, ocorre uma considerável redução no volume. ${ }^{8,9}$ Esse decréscimo foi atribuído por ele à variação no raio da ligação simples que acompanha a mudança na valência dos átomos. ${ }^{11} \mathrm{~A}$ transferência de elétrons de ou para um átomo é seguida por uma mudança em seu raio metálico. Essa variação associada com a mudança na valência foi calculada por Pauling através da expressão

$$
D(n)=D(1)-A \log n
$$

onde $D(n)$ é o comprimento (raio) da ligação para um número de ligação fracionária $n$ e $D(1)$ é o raio covalente.$^{1-9} O$ número de ligação $n$ é dado pela razão entre a valência do átomo e sua 'ligância': $v / L$. A 'ligância' é o número de coordenação. ${ }^{8} \mathrm{O}$ valor do coeficiente $A$ foi inicialmente designado por Pauling como $0,6 \AA ̊$ e sua função é corrigir a equação de modo a contabilizar a energia de ressonância. A equação (9) contabiliza ambos os efeitos no cálculo do raio metálico: o da mudança na valência e o da ressonância não-sincronizada, contudo é ineficaz quando o número de ligantes associado a um dado átomo é superior a doze. ${ }^{6}$

Posteriormente, Pauling ${ }^{9,13}$ refinou sua equação tornando-a apropriada para sistemas onde o número de ligantes é diferente de doze, reescrevendo-a como

$$
D(n)=D(1)-A \log \{n[1+B(v-1)]\}
$$

e assinalou o valor de $0,7 \AA$ para o coeficiente $A$. O número de ligação $n$ é substituído pela ordem de ligação $n[1+B(v-1)]$. Esse termo envolve uma melhor correção para contabilizar a energia de ressonância. $O$ fator $v-1$ é usado porque não há energia de ressonância para $v=1$. Pauling assume um valor de 0,064 para $B$ de modo a obter melhor concordância com dados experimentais. Tanto o valor de $A$ quanto o de $B$ são arbitrários e foram acrescentados na tentativa de obter valores compatíveis com resultados experimentais. 
Na região próxima do equilíbrio a energia de ressonância incrementa em magnitude com a diminuição na distância interatômica, resultando no encurtamento do comprimento da ligação. ${ }^{9,13} \mathrm{O}$ conjunto de valores para o raio de uma ligação covalente simples e para o caso em que o átomo se encontra ligado a outros 12 , permitiu a Pauling verificar que quando se computa a ressonância nestes cálculos, há um discreto encurtamento no comprimento das ligações. Isso está de acordo com as previsões da teoria RVB em que as ligações mais curtas têm maior probabilidade de mudar de posição de forma não-sincronizada do que as ligações mais longas. $^{6}$ Outra estimativa aproximada feita por
Pauling ${ }^{12}$ foi considerar que o raio metálico de um átomo que possui um elétron adicional pode ser tomado como sendo igual ao do próximo átomo na tabela periódica. Esta hipótese o levou a resultados satisfatoriamente próximos dos experimentais. ${ }^{12}$

Em paralelo à sua classificação dos átomos em hipo, buffers e hipereletrônicos, Pauling determinou a valência de cada metal através da curva PaulingSlater. ${ }^{1,6,8} \mathrm{O}$ gráfico da Figura 2 mostra a valência para os elementos do primeiro período longo. A valência de cada átomo foi determinada levando em conta que dos nove orbitais spd híbridos, 0,72 estão presentes como orbital metálico. ${ }^{8}$

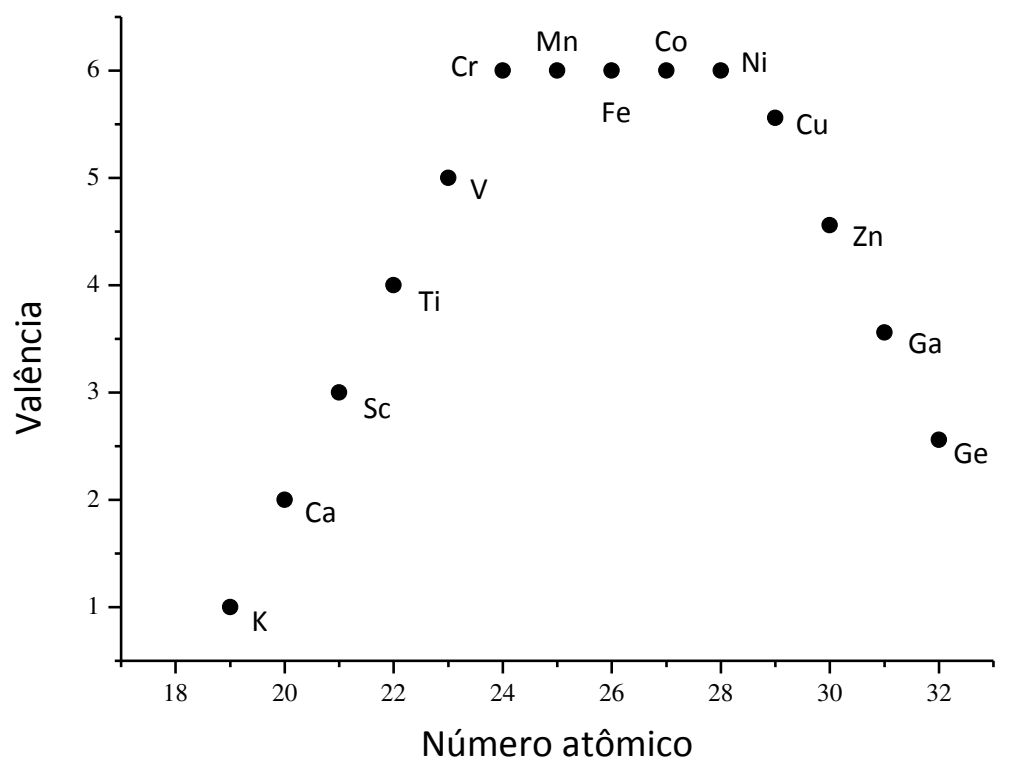

Figura 2. Valência metálica de alguns átomos de acordo com a classificação de Pauling ${ }^{1,6}$

A redução nas distâncias interatômicas dos metais na mesma sequência em que os átomos aparecem no gráfico da Figura 2, levou Pauling à conclusão que se tratava do aumento no número de ligações. ${ }^{13}$ Uma vez que do $\mathrm{Cr}$ até o $\mathrm{Ni}$ as distâncias permaneciam aproximadamente constantes, Pauling concluiu que não haveria mais mudança no número de ligações formadas por esses átomos. O valor máximo de 6 corresponde ao número de orbitais de ligação que podem ser formados por estes elementos a partir dos nove orbitais $s, p$ e $d$ híbridos. ${ }^{13}$ Do $\mathrm{Cu}$ em diante, o número de ligações começa a diminuir.

Apesar de não ser mostrado na Figura 2, as distâncias interatômicas dos metais no quarto e quinto períodos da tabela periódica também decrescem até um mínimo ( $R u$ e $O s$ ) que corresponde a 8 elétrons de valência. Pauling verificou que as propriedades magnéticas destes metais eram diferentes, mas aceitáveis caso os oito elétrons fossem usados na formação de ligações. Ele Rev. Virtual Quim. |Vol 4| |No. 2| |130-145| interpretou esse valor como a máxima valência que estes átomos podem assumir a partir dos nove orbitais spd híbridos, sendo que 0,72 consiste no orbital metálico. ${ }^{15} \mathrm{~A}$ proposta de que metais de transição podem formar muitas ligações covalentes permitiu a Pauling usar a teoria RVB para explicar as propriedades de muitos compostos de um modo mais efetivo do que teria sido possível sem esta hipótese. ${ }^{1-8}$ As muitas ligações formadas pelos metais em complexos de metais de transição é um campo onde o conceito da ressonância não-sincronizada aplica-se com sucesso. Pauling fez uso da ideia intuitiva da ressonância não-sincronizada para demonstrar a estabilidade de alguns complexos obtida pela energia de ressonância. Nestes sistemas, os metais formam um número de ligações maior do que suas valências permitem, o que pode ser compreendido em termos da ressonância não-sincronizada das ligações covalentes. Depois da abordagem empírica feita por Pauling, ele também previu teoricamente o valor do 
orbital metálico e o número de estruturas ressonantes sincronizadas e não-sincronizadas através de um tratamento estatístico, o que será visto na próxima seção onde serão apresentadas sucintamente as equações utilizadas por Pauling nestes cálculos.

\section{Cálculo do número de estruturas RVB}

Através de cálculos estatísticos de algumas propriedades eletrônicas dos átomos como valência, número de coordenação, momento magnético, Pauling obteve teoricamente o número de estruturas ressonantes sincronizadas e não-sincronizadas por átomo e o valor do orbital metálico. ${ }^{11}$ As duas expressões para o cálculo do número de estruturas ressonantes levam em conta a valência $(v)$ dos átomos e o número de ligantes $(L)$. Representar-se-á por $R_{S}$ a equação que permite o cálculo do número de estruturas ressonantes sincronizadas e por $R_{N S}$ a que leva ao cálculo das estruturas ressonantes nãosincronizadas. Elas são dadas por: ${ }^{6}$

$$
\begin{gathered}
R_{S}=\frac{v^{v / 2}(L-v)^{(L-v) / 2} L !}{L^{L / 2} v !(L-v) !} \\
R_{N S}=\frac{v^{v / 2}(L-v)^{(L-v) / 2} L !}{L^{L / 2} v !(L-v) !}\left(\frac{L-v}{L-v+1}+1+\frac{v}{v+1}\right)
\end{gathered}
$$

Para um cristal metálico, a ressonância nãosincronizada permite que o número de ligações por átomo seja $v-1, \quad v$ e $v+1$, correspondendo respectivamente à $M^{+}, M^{0}$ e $M^{-}$, em concordância com o princípio da eletroneutralidade. ${ }^{10} \mathrm{~A}$ partir deste tratamento, Pauling ${ }^{11}$ obteve teoricamente um intervalo de valores entre 0,714 e 0,684 para o orbital metálico, uma estimativa que concorda satisfatoriamente com o valor 0,72 obtido a partir de dados experimentais do momento magnético de alguns metais e ligas. ${ }^{1-8} \mathrm{O}$ gráfico da Figura 3 mostra a variação do número de estruturas ressonantes nãosincronizadas por átomo em função da valência para um elemento qualquer com número de ligantes igual a doze. Os valores foram obtidos com o uso da Equação 12.

O número de estruturas ressonantes nãosincronizadas decresce para valores da valência maiores do que $1 / 2$ do número de ligantes. Em outras palavras, o número de ligantes ideal para um dado metal é igual ao dobro de sua valência $(L=2 v)$, onde ocorre o maior número de estruturas ressonantes não-sincronizadas por átomo e onde prevalece o efeito estabilizante. ${ }^{1-14}$ Pauling constatou que em alguns metais onde o número de ligantes é superior a $2 v$, há um grupo de ligantes mais próximos e outro grupo mais distante, ${ }^{6}$ de modo que o fenômeno da ressonância ocorre efetivamente no grupo de átomos mais próximos. O arranjo atômico mais estável é aquele onde os átomos possuem o maior número possível de ligantes, ${ }^{6,8}$ sendo as estruturas cristalinas cúbica e hexagonal as que permitem o maior número $(L=12)$. Cerca de $80 \%$ dos elementos químicos e também muitas ligas cristalizam em uma dessas duas formas. ${ }^{8}$ Em alguns metais, no entanto, o efeito repulsivo de pares de elétrons isolados na camada de valência impede o aumento no número de ligantes. ${ }^{8}$

A obtenção teórica do valor correto do orbital metálico e do número de estruturas ressonantes fornece suporte adicional à teoria RVB e sugere que os conceitos nela envolvidos podem ajudar na conexão com o tratamento mais convencional dos metais pela mecânica quântica. ${ }^{11}$ 


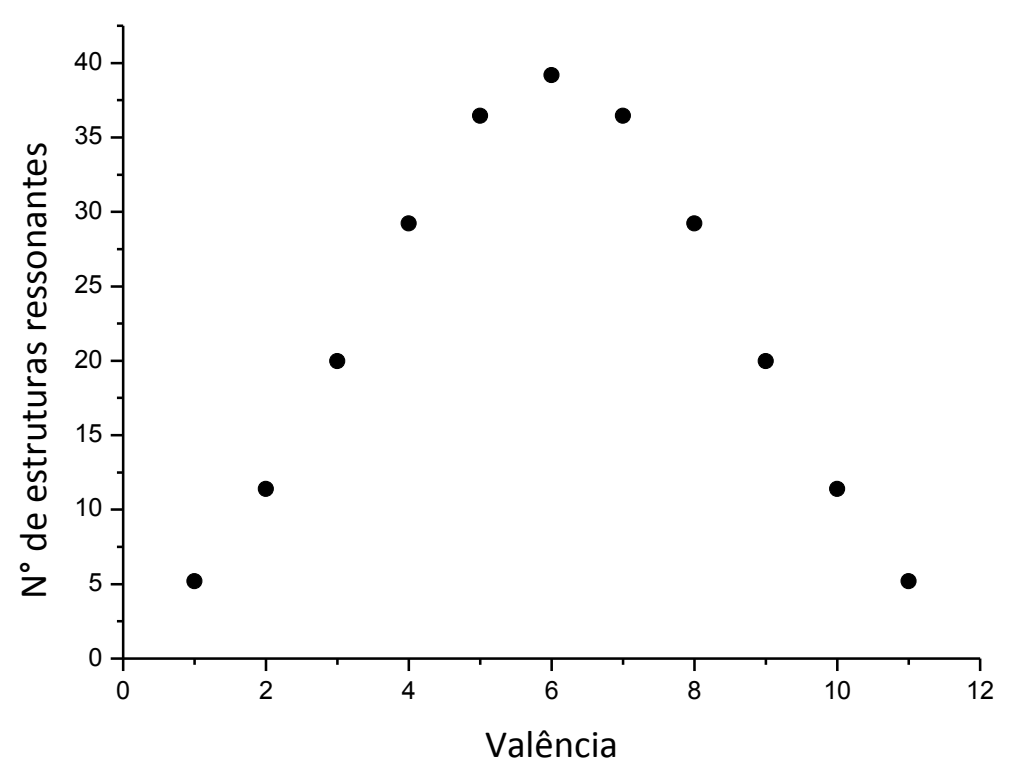

Figura 3. Número de estruturas ressonantes não-sincronizadas em função da valência para um metal arbitrário com número de coordenação igual a doze $\mathrm{e}^{1,8}$

\section{Uma visão química do estado sólido}

Devido ao progresso da teoria RVB, Pauling expandiu o leque de aplicações da mesma para além dos metais e ligas e investigou outros assuntos relevantes como a supercondutividade ${ }^{15}$ e 0 magnetismo. ${ }^{16}$ Pode-se dizer que sua teoria é uma visão química do estado sólido. Pesquisadores estão obtendo sucesso na aplicação dos conceitos da teoria RVB em seus estudos, em particular, na elucidação mais apropriada de alguns fenômenos, o que levou recentemente a um novo despertar de interesse pelo tema. ${ }^{17-31}$ Descrições qualitativas em alguns casos e quantitativas em outros foram obtidas e estão em andamento. ${ }^{17-31}$ Apesar disso, a teoria ainda permanece pouco conhecida entre os químicos, o que pode ser visto nas citações dos trabalhos de Pauling que tratam especificamente da teoria RVB. ${ }^{6}$

É importante ressaltar que Pauling mostrou ${ }^{6}$ a equivalência entre sua teoria e a de bandas para metais, apontando que elas são compatíveis e complementares. Contudo, a vantagem da teoria RVB é que ela torna mais fácil e intuitiva a discussão das propriedades dos sistemas em estudo com a natureza dos átomos do qual são constituídos, o que levou Pauling a considerar sua proposta mais apropriada para a investigação de fenômenos que se dão pela transferência de elétrons. ${ }^{1-16}$ Além disso, Pauling não encontrou nenhum vestígio do orbital metálico em cálculos de estrutura de bandas, ${ }^{6}$ o que contribuiu para que desenvolvesse sua própria linguagem.
Estudos do mecanismo RVB da transferência de carga são passíveis de análise não apenas por cálculos do tipo Valence Bond, mas também através de cálculos de orbitais moleculares. ${ }^{17-25}$ Essa estratégia vem sendo usada com sucesso uma vez que cálculos Valence Bond requerem elevado custo computacional, ${ }^{23,32}$ o que inviabiliza sua empregabilidade e restringe seu uso a sistemas muito pequenos. ${ }^{27}$ Além disso, a teoria RVB está sendo empregada ${ }^{17-25}$ de modo qualitativo na interpretação de resultados teóricos obtidos com métodos de estrutura eletrônica diversos. Estes resultados reforçam a proposta de Pauling e contribui para a consolidação de sua teoria como uma alternativa às tradicionais teorias usadas para descrever o estado sólido e também fenômenos que se dão pela transferência de carga.

Estudos diversos como a supercondutividade, ${ }^{17-}$ 20,26 a carcinogênese química, ${ }^{21}$ o mecanismo de interação de moléculas com superfícies metálicas, ${ }^{22}$ a condutividade elétrica no lítio, ${ }^{23}$ a formação e estabilidade do $\mathrm{O}_{4}{ }^{24}$, o magnetismo, ${ }^{25}$ os metais, ligas e compostos intermetálicos, ${ }^{27}$ a condutividade elétrica em sistema orgânicos $1 \mathrm{D},{ }^{28}$ a implementação de novos métodos computacionais, ${ }^{29}$ etc. são exemplos da versatilidade da teoria RVB e uma demonstração clara de sua ampla empregabilidade. Apesar de seu sucesso, a teoria RVB de Pauling é pouco aceita na comunidade científica que desenvolve pesquisas com metais. A teoria de bandas é amplamente empregada em detrimento da teoria proposta por Pauling, o que não significa necessariamente que os conceitos de sua teoria sejam inadequados. Ainda que poucos grupos de pesquisa 
no mundo insistam em usar os conceitos de Pauling, os resultados obtidos são animadores como mostra a literatura. $^{1-30}$

\section{Agradecimentos}

Ao Conselho Nacional de Desenvolvimento Científico e Tecnológico (CNPq) pelo suporte financeiro.

Ao professor Dr. Antonio Carlos Pavão pelas muitas discussões e ensinamentos a respeito da teoria RVB.

\section{Referências Bibliográficas}

${ }^{1}$ Herman, Z. S. Em Pauling's Legacy: Modern Modelling of the Chemical Bond; Maksić, Z. B.; OrvilleThomas, W. J., eds.; Elsevier Science B. V.: Amsterdam, 1999, cap. 28.

2 Pauling, L.; Herman, Z. S.; Valence Bond Theory and Chemical Structure, Elsevier Science Publishers B. V.: Amsterdam, 1990.

3 Pauling, L.; Herman, Z. S.; Advances in Boron and the Boranes, VCH Publishers: New York, 1988.

${ }^{4}$ Pauling, L.; Herman, Z. S.; Modelling of Structure and Properties of Molecules, Ellis Horwood: England, 1987.

${ }^{5}$ Pauling, L.; Herman, Z.S.; Chemical Bonding Models, VCH Publishers: Deerfield Beach, FL, 1986.

${ }^{6}$ a) Pauling, L. Pure \& Appl. Chem. 1989, 61, 2171; [CrossRef] b) Kamb, B.; Pauling, L. Proc. Natl. Acad. Sci. USA 1985, 82, 8284; [CrossRef] c) Pauling, L.; Herman, Z. S. J. Chem. Ed. 1985, 62, 1086; [CrossRef] d) Pauling, L. J. Solid State Chem. 1984, 54, 297; [CrossRef] e) Pauling, L.; Herman, Z. S. J. Chem. Ed. 1984, 61, 582; [CrossRef] f) Pauling, L. Proc. Natl. Acad. Sci. USA 1983, 80, 3871; [CrossRef] g) Pauling, L. Proc. R. Soc. A 1977, 356, 433; [CrossRef] h) Pauling, L. Nature 1961, 189, 656; [CrossRef] i) Pauling, L. Science 1956, 123, 255; [CrossRef] j) Pauling, L.; Pauling, P. Acta Cryst. 1956, 9, 127; [CrossRef] k) Pauling, L. J. Electrochem. Soc. 1951, 98, 518; [CrossRef] I) Pauling, L. Proc. R. Soc. A 1949, 196, 343; [CrossRef] m) Pauling, L. Physica 1949, 15, 23; [CrossRef] n) Pauling, L. Nature 1948, 161, 1019; [CrossRef] o) Pauling, L. Ewing, F. J.; Rev. Mod. Phys. 1948, 20, 112; [CrossRef] p) Pauling, L. J. Am. Chem. Soc. 1947, 69, 542; [CrossRef] q) Pauling, L. Phys. Rev. 1938, 54, 899. [CrossRef]
7 Pauling, L.; Pauling, P.; Chemistry, W. H. Freeman and Company: San Francisco, 1975.

${ }^{8}$ Pauling, L.; The Nature of the Chemical Bond and the Structure of Molecules and Crystals: An Introduction to Modern Structural Chemistry, Cornell University Press: New York, 1960.

9 a) Pauling, L. Proc. Natl. Acad. Sci. USA 1989, 86, 9637; [CrossRef] b) Pauling, L.; Kamb, B. Z. Kristallogr. 1959, 112, 472; [CrossRef] c) Tunell, G.; Pauling, L. Acta Cryst. 1952, 5, 375; [CrossRef] d) Pauling, L.; Soldate, A. M. Acta Cryst. 1948, 1, 212; [CrossRef] e) Pauling, L.; Kamb, B. Proc. Natl. Acad. Sci. USA 1986, 83, 3569; [CrossRef] f) Pauling, L. Proc. Natl. Acad. Sci. USA 1984, 81, 1918; [CrossRef] g) Pauling, L. Proc. Natl. Acad. Sci. USA 1977, 74, 2614; [CrossRef] h) Pauling, L. Proc. Natl. Acad. Sci. USA 1976, 73, 4290; [CrossRef] i) Pauling, L. Acta Cryst. B 1968, 24, 5; [CrossRef] j) Pauling, L. Acta Cryst. 1957, 10, 685; [CrossRef] k) Pauling, L. Acta Cryst. 1957, 10, 374; [CrossRef] I) Pauling, L. J. Phys. Chem. 1954, 58, 662; [CrossRef] m) Pauling, L. Acta Cryst. 1951, 4, 138; [CrossRef] n) Waser, J.; Pauling, L. J. Chem. Phys. 1950, 18, 747. [CrossRef]

10 a) Pauling, L.; Kamb, B. Am. Mineral. 1982, 67, 817; [Link] b) Pauling, L. Am. Mineral. 1980, 65, 321; [Link] c) Pauling, L. J. Chem. Soc. 1948, 1461. [CrossRef]

11 a) Pauling, L. Proc. Natl. Acad. Sci. USA 1987, 84, 4754; [CrossRef] b) Pauling, L.; Kamb, B. Proc. Natl. Acad. Sci. USA 1985, 82, 8286; [CrossRef] c) Pauling, L. Proc. Natl. Acad. Sci. USA 1950, 36, 533. [CrossRef]

12 Pauling, L.; Quantum Theory of Atoms, Molecules, and the Solid State, A Tribute to John C. Slater, Academic Press: New York, 1966.

13 a) Pauling, L. Phys. Rev. Lett. 1981, 47, 277; [CrossRef] b) Pauling, L. Proc. Natl. Acad. Sci. USA 1978, 75, 569; [CrossRef] c) Pauling, L. Proc. Natl. Acad. Sci. USA 1978, 75, 12; [CrossRef] d) Pauling, L. Acta Cryst. B 1978, 34, 746; [CrossRef] e) Pauling, L. Proc. Natl. Acad. Sci. USA 1977, 74, 5235; [CrossRef] f) Pauling, L. Proc. Natl. Acad. Sci. USA 1975, 72, 4200; [CrossRef] g) Pauling, L. Proc. Natl. Acad. Sci. USA 1975, 72, 3799; [CrossRef] h) Pauling, L.; Keaveny, I.: Wave Mechanics, Wiley: New York, 1973.

${ }^{14}$ Pauling, L.; Wilson, E.: Introduction to Quantum Mechanics, McGraw-Hill Book Company: New York, 1935.

15 a) Pauling, L. Proc. Natl. Acad. Sci. USA 1991, 88, 9208; [CrossRef] b) Pauling, L.; High Temperature Superconductivity: The First Two Years, Gordon and Breach Scientific Publishers: New York, 1989; Pauling, L. Phys. Rev. Lett. 1987, 59, 225; [CrossRef] c) Pauling, Rev. Virtual Quim. |Vol 4 | | No. 2| |130-145| 
L. Proc. R. Soc. A 1981, 378, 207; [CrossRef] d) Pauling, L. Proc. Natl. Acad. Sci. USA 1968, 60, 59. [CrossRef]

16 Pauling, L. Proc. Natl. Acad. Sci. USA 1953, 39, 551. [CrossRef]

${ }^{17}$ a) Bastos, C. C.; Costa, M. B. S.; Pavão, A. C. Int. J. Quantum Chem. 2010, 110, 2088; [CrossRef] b) Bastos, C. C.; Tese de Doutorado, Universidade Federal de Pernambuco, Brasil, 2012.

${ }^{18}$ Costa, M. B. S.; Dissertação de Mestrado, Universidade Federal de Pernambuco, Brasil, 2010. [Link]

19 a) Rocha, J. A. M. R.; Pavão, A. C. Physica C 2004, 411, 148; [CrossRef] b) Rocha, J. A. M. R.; Tese de Doutorado, Universidade Federal de Pernambuco, Brasil, 2005. [Link]

${ }^{20}$ Pavão, A. C.; Taft, C. A.; Guimarães, T. C. F.; Leão, M. B. C.; Mohallem, J. R.; Lester, J. W. A. J. Phys. Chem. A 2001, 105, 5. [CrossRef]

${ }^{21}$ a) Leão, M. B. C.; Pavão, A. C.; J. Mol. Struct.Theochem 2001, 539, 297; [CrossRef] b) Leão, M. B. C.; Longo, R. L.; Pavão, A. C. J. Mol. Struct.-Theochem 1999, 490, 145; [CrossRef] c) Leão, M. B. C.; Pavão, A. C. Int. J. Quantum Chem. 1997, 62, 323. [CrossRef]

22 a) Ferreira, J. V.; Pavão, A. C. Surf. Sci. 2008, 602, 1964; [CrossRef] b) Guimarães, T. C. F.; Pavão, A. C.; Taft, C. A.; Lester, W. A. Phys. Rev. B 1999, 60, 789; [CrossRef] c) Pavão, A. C.; Guimarães, T. C. F.; Lieb, S. K.; Taft, C. A.; Lester, W. A. J. Mol. Struct.-Theochem 1998, 458, 99; [CrossRef] d) Guimarães, T. C. F.; Pavão, A. C.; Taft, C. A.; Lester, W. A. Phys. Rev. B 1997, 56, 7001; [CrossRef] e) Pavão, A. C.; Soto, M. M.; Lester, W. A.; Lie, S. K.; Hammond, B. L.; Taft, C. A. Phys. Rev. B 1994, 50, 1868; [CrossRef] f) Pavão, A. C.; Braga, M.; Taft, C. A.; Hammond, B. L.; Lester, W. A. Phys. Rev. B 1991, 43, 6962. [CrossRef]

${ }^{23}$ Mohallem, J. R.; Vianna, R. O.; Quintão, A. D.; Pavão, A. C.; McWeeny, R. Z. Phys. D 1997, 42, 135. [CrossRef]

${ }^{24}$ a) Paula, J. C. F.; Pavão, A. C.; Taft, C. A. J. Mol. Struct.-Theochem 2004, 713, 33; [CrossRef] b) Pavão, A. C.; Paula, J. C. F.; Custódio, R.; Taft, C. A. Chem. Phys. Lett. 2003, 370, 789; [CrossRef] c) Pavão, A. C.; Seabra, G. M.; Taft, C. A. J. Mol. Struct.-Theochem 1995, 335, 59. [CrossRef]

25 a) Pavão, A. C.; Santos, J. R. S.; Taft, C. A. Mol. Simul. 2009, 35, 287; [CrossRef] b) Pavão, A. C.; Taft, C. A.; Hammond, B. L.; Lester, W. A. Phys. Rev. B 1989, 40, 2879. [CrossRef]

${ }^{26}$ a) Yao, Y.; Tse, J. S.; Klug, D. D. Phys. Rev. B 2009,
80, 094106; [CrossRef] b) Phillips, J. C. Chem. Phys. Lett. 2008, 451, 98; [CrossRef] c) Krasinkova, M. V. Physica C 2006, 449, 33; [CrossRef] d) Sachdev, S. Rev. Mod. Phys. 2003, 75, 913; [CrossRef] e) Zhang, H.; Cheng, L. L.; Qin, X. C.; Zhao, Y. Phys. Rev. B 2000, 61, 1618; [CrossRef] f) Wong-Ng, W.; Melamud, M.; Bennett, L. H.; Watson, R. E. Physica C 1999, 322, 177; [CrossRef] g) Larsson, S. Chem. Phys. 1998, 236, 133; [CrossRef] h) Krasin'kova, M. V. Tech. Phys. 1998, 43, 1347; [CrossRef] i) Krasin'kova, M. V. Tech. Phys. Lett. 1997, 23, 681; [CrossRef] j) Chakravarty, S.; Gelfand, M. P.; Kivelson, S. Science 1991, 254, 970. [CrossRef]

27 a) Liao, C. N.; Chern, C. H. J. Magn. Magn. Mater. 2011, 323, 232; [CrossRef] b) Edwards, P. P.; Lodge, M. T. J.; Hensel, F.; Redmer, R. Phil. Trans. R. Soc. A 2010, 368, 941; [CrossRef] c) Liu, J.; Ma, T.; Tong, H.; Luo, W.; Yan, M. J. Magn. Magn. Mater. 2010, 322, 940; [CrossRef] d) Nissenbaum, D.; Spanu, L.; Attaccalite, C.; Barbiellini, B.; Bansil, A. Phys. Rev. B 2009, 79, 035416; [CrossRef] e) Fukuhara, M.; Takahashi, M.; Kawazoe, Y.; Inoue, A. J Alloy Compd. 2009, 483, 623; [CrossRef] f) Aullón, G.; Alvarez, S. Theor. Chem. Acc. 2009, 123, 67; [CrossRef] g) Szentpály, L. J. Am. Chem. Soc. 2008, 130, 5962; [CrossRef] h) Fukuhara, M.; Takahashi, M.; Kawazoe, Y.; Inoue, A. Appl. Phys. Lett. 2007, 90, 073114; [CrossRef] i) Xiaobo, L.; Youqing, X.; Yaozhuang, N.; Hongjian, P. Physica B 2007, 394, 27; [CrossRef] j) Xiaobo, L.; Youqing, X.; Yaozhuang, N.; Hongjian, P. Physica B 2007, 393, 119; [CrossRef] k) Guoa, Y. R.; Panb, Q. J.; Weia, Y. D.; Lia, Z. H.; Li, X. J. Mol. Struct.Theochem 2004, 676, 55; [CrossRef] Harcourt, R. D.; Styles, M. L. J. Phys. Chem. A 2003, 107, 3877; [CrossRef] I) Quintão, A. D.; Vianna, R. O. Int. J. Quant. Chem. 2001, 81, 76; [CrossRef] Quintão, A. D.; Vianna, R. O.; Mohallem, J. R. Eur. Phys. J. D 1999, 6, 89; [CrossRef] m) Aurelio, G.; Guillermet, A. F. J. Alloys Compd. 1999, 292, 31; [CrossRef] n) Vianna, R. O.; Chacham, H. J. Chem. Phys. 1998, 109, 10316; [CrossRef] o) Edwards, P. P.; Johnston, R. L.; Rao, C. N. R.; Tunstall, D. P.; Hensel, F. Phil. Trans. R. Soc. Lond. A 1998, 356, 5; [CrossRef] p) Klein, D. J.; Schmalz, T. G.; Garcriaaa-Bach, M. A.; Valenti, R.; Živković, T. P. Phys. Rev. B 1991, 43, 719; [CrossRef] q) Gross, K. D.; Riegel, D.; Zeller, R. Phys. Rev. Lett. 1989, 63, 1176; [CrossRef] r) Sermon, P. A. Chem. Soc. Rev. 1987, 16, 339; [CrossRef] s) Harcourt, R. D. J. Phys. B: Atom. Molec. Phys. 1974, 7, L41. [CrossRef]

28 a) Bag, P.; Itkis, M. E.; Pal, S. K.; Donnadieu, B.; Tham, F. S.; Park, H.; Schlueter, J. A.; Siegrist, T.; Haddon, R. C. J. Am. Chem. Soc. 2010, 132, 2684; [CrossRef] b) Shimizu, A.; Uruichi, M.; Yakushi, K.; Matsuzaki, H.; Okamoto, H.; Nakano, M.; Hirao, Y.; Matsumoto, K.; Kurata, H.; Kubo, T. Angew. Chem. Int. 
Ed. 2009, 48, 5482; [CrossRef] c) Haddon, R. C.; Sarkar, A.; Pal, S. K.; Chi, X.; Itkis, M. E.; Tham, F. S. J. Am. Chem. Soc. 2008, 130, 13683; [CrossRef] d) Torrens, F.; Castellanob, G. Curr. Prot. 2009, 6, 204; [CrossRef] e) Pal, S. K.; Itkis, M. E.; Tham, F. S.; Reed, R. W.; Oakley, R. T.; Donnadieu, B.; Haddon, R. C. J. Am. Chem. Soc. 2007, 129, 7163; [CrossRef] f) Mandal, S. K.; Samanta, S.; Itkis, M. E.; Jensen, D. W.; Reed, R. W.; Oakley, R. T.; Tham, F. S.; Donnadieu, B.; Haddon, R. C. J. Am. Chem. Soc. 2006, 128, 1982; [CrossRef] g) Pal, S. K.; Itkis, M. E.; Tham, F. S.; Reed, R. W.; Oakley, R. T.; Haddon, R. C. Science 2005, 309, 281; [CrossRef] h) Ivanciuc, O.; Klein, D. J.; Bytautas, L. Carbon 2002, 40, 2063; [CrossRef] i) Klein, D. J.; Bytautas, L.; J. Phys. Chem. A 1999, 103, 5196. [CrossRef]

29 a) Beach, K. S. D. Phys. Rev. B 2009, 79, 224431; [CrossRef] b) Marchi, M.; Azadi, S.; Casula, M.; Sorella, S. J. Chem. Phys. 2009, 131, 154116. [CrossRef]

30 a) Hedegard, E. D.; Bendix, J.; Sauer, S. P. A. J. Mol. Struct.-Theochem 2009, 913, 1; [CrossRef] b) Duffy, J. A.; Macphee, D. E. J. Phys. Chem. B 2007, 111, 8740. [CrossRef]
31 a) Anderson, P. W. Phys. Today 2008, 61, 8; [CrossRef] b) Anderson, P. W. Phys. Rev. Lett. 2006, 96, 17001; [CrossRef] c) Anderson, P. W. Phys. Rev. B 1990, 42, 2624; [CrossRef] d) Liang, S.; Doucot, B.; Anderson, P. W. Phys. Rev. Lett. 1988, 61, 365; [CrossRef] e) Anderson, P. W.; Zou, Z. Phys. Rev. Lett. 1988, 60, 132; [CrossRef] f) Wheatley, J. M.; Hsu, T. C.; Anderson, P. W. Phys. Rev. B 1988, 37, 5897; [CrossRef] g) Zou, Z.; Anderson, P. W. Phys. Rev. B 1988, 37, 627; [CrossRef] h) Anderson, P. W.; Baskaran, G.; Zou, Z.; Hsu, T. Phys. Rev. Lett. 1987, 58, 2790; [CrossRef] i) Baskaran, G.; Zou, Z.; Anderson, P. W. Solid State Commun. 1987, 63, 973; [CrossRef] j) Anderson, P. W. Science 1987, 235, 1196; [CrossRef] k) Anderson, P. W. Mater. Res. Bull. 1973, 8, 153. [CrossRef]

32 Larsson, S. Chem. Phys. 1998, 236, 133. [CrossRef]

33 Truhlar, D. G. J. Chem. Educ. 2007, 84, 781. [CrossRef] 